\title{
Online Monitoring System of the Mine Main Fan
}

\author{
ZHANG Hongwei \\ Management Training Center of HeiLongJiang Electric Power Limited Company \\ Harbin 150030, China \\ Zh_hongclj@163.com
}

\begin{abstract}
Monitoring system uses upper and lower machine model. The machine adopts the simple operation, reliable performance of PLC acquisition of main fan for each parameter and alarm control. In order to ensure that the fan monitoring system reliability and real time nature, based on the $\mathrm{VC}++$ and SQL Server to develop a set of computer monitoring system. Monitoring software system and data acquisition and processing hardware system connected by a RS-485 bus system. Computer to other computers in a network or through the monitoring host forwarding see fan monitoring interface.
\end{abstract}

Keywords-online monitoring;main fan; PCL; VC++

\section{INTRODUCTION}

According to the coal mine enterprise's production characteristics, two sets of main fan in air shaft is the oversize load key equipment of mine production. Responsibility to the underground mine conveying fresh air, exhausting harmful gas, guarantee the safety of mine production task. At the same time, because the main fan working in the dirty air, voltage is higher, and the current failure probability are large, they are recessive, unpredictable, serious harm to production. The existences of hidden faults seriously affect all the economic and safe operation[1]. Therefore, design a set of perfect function, safety and reliability, convenient operation of the mine main fan on line monitoring system of main fan operation, control, and the various parameters and operating characteristics of timely, accurate monitoring, to ensure mine safety and raise economic efficiency is important.

\section{SYSTEM FUCTION}

The system focuses on the study of coal mine fan remote safety monitoring technique theory and experimental verification of problems. The system mainly completes the data processing, storage and displaying the state of work, and with the upper network and Internet network, realize the equipment remote monitoring, signal analysis in one of the equipment system[2].

\section{A. System components}

1) Parameter acquisition section

2) Signal conversion section

3) The data processing section

4) Display output section

The data processing section, a display output portion is mainly completed by PLC controller.

\section{B. The main monitoring parameters}

1) Real time monitoring the performance parameters of the fan,include Static pressure,total pressure, efficiency

2) Real time monitoring of the air volume and entrance temperature of the fan.

3) Real time monitoring of motor running current and voltage, power.

4) Real time monitoring of fan and motor bearing temperature, motor winding temperature.

5) Real time monitoring of vibration of motor shaft. System diagram in Figure 1

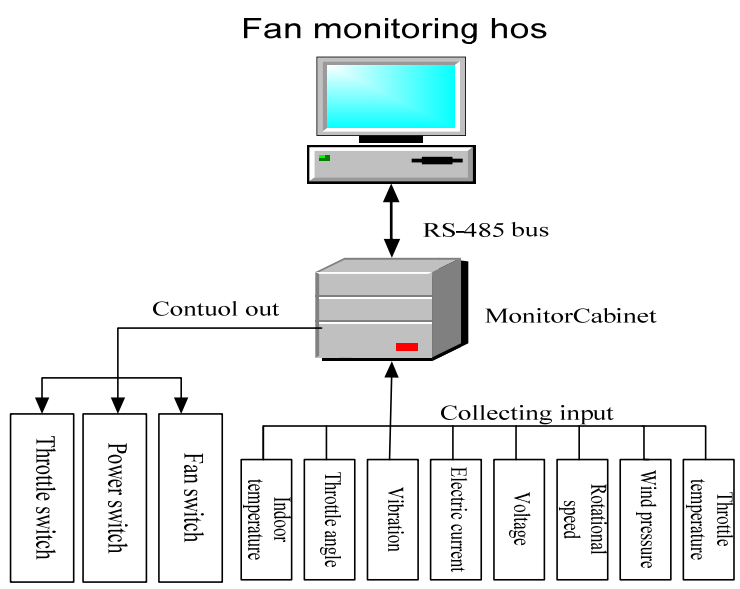

Figure1. System block diagram

\section{HARDWARE DESIGN}

The system consists of PLC measurement and control system, high voltage power distribution system, communication system and industrial computers. Siemens system with S7-300 as the core, including temperature sensor, pressure sensor, vibration sensor, current transformer, voltage transducer, displacement sensor through which measured throttle angles, collecting fan operation control of relevant parameters, processing and uploaded to the server, by VC+ + development of the client processing, stored in the SQL database, to achieve real-time monitoring, real time alarm and draw the daily report, dynamic trend curve.

\section{A. Electric parameters}

The transmission of electric parameters is electric parameters such as motor current, voltage, power and power 
factor. Selection of high precision, reliability of the electric quantity acquisition module will come from the voltage, the current transformer two side voltages, currents into standard signals to access S7-300.

\section{B. Vibration signal}

System requires two Typhoon aircraft horizontal and vertical vibration intensity, explosion-proof type vibration sensor, the output from 4 to $20 \mathrm{~mA}$ current signal, access to the S7-300 simulation module. When the main fan is bearing, the vibration is larger than $1.6 \mathrm{~mm} / \mathrm{s}$ alarm, more than $4.3 \mathrm{~mm} / \mathrm{s}$ tripping. [3]

\section{Bearing temperature measurement}

Continuous monitoring the bearing temperature and motor bearing temperature of the fan, is also an important task of fan monitoring. Motor bearing temperature and wind turbine bearing temperature sensor for motor factory in embedded is PT100 platinum thermal resistance, and there are three wire lead fan body electrical junction box Maintain the Integrity of the Specifications.

\section{Negative pressure and volume parameters}

According to the coal mine main fan site " performance parameters determination method of " MT 421-1996, the people's Republic of China Ministry of coal industry 199612-30 approval, P1 arrangement of measuring points in a fan annular section, horizontal, vertical two diameter and the chamber wall and the outer edge of the core cylinder intersection a, B, C, D, e, F, G, h, shown in Figure 2, P2 measuring point arrangement in the connecting cylinder with circular cross section, horizontal, vertical two diameter and the chamber wall nodal a, B, C, D, see figure 3 .

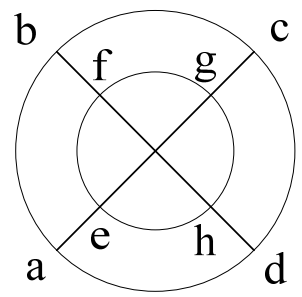

Figure2. P1 measuring point

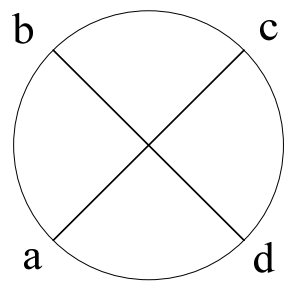

Figure3. P2 measuring point
Negative pressure by the pressure sensor directly measured by negative pressure air flow calculation, the formula is as follows,

$$
q=s_{1} \times s_{2} \sqrt{\left(p_{1}-p_{2}\right) / 2 \rho\left(s_{1}^{2}-s_{2}^{2}\right)}
$$

In formula, $S_{1} 、 S_{2}$ is the measure of fan body two cross-sectional areas.

$p_{1} 、 p_{2}$ is the negative pressure of two cross-section.

$\rho$ is the air density.

\section{SOFTWARE DESIGN}

The system is controlled by the industrial control computer as the core, with a variety of peripheral equipment, under the control of software, data acquisition, analysis, charts and other form are displayed on a display device, and transmits it to a designated location[4].

In order to ensure that the fan monitoring system reliability and real time nature, based on the VC++ and SQL Server to develop a set of computer monitoring system. $\mathrm{VC}++$ and SQL Server is Microsoft company flagship program development and database products, strong functions, wide application, technology is mature. Developments of the $\mathrm{VC}++$ program, small volume and high efficiency, suitable for ventilator monitoring and control, and the program development process of flexible. SQL Server database has fast speed, high availability, advantages of safe and reliable, therefore, is the wind machine monitoring software ideal database platform. Monitoring software system and data acquisition and processing hardware system connected by a RS-485 bus, measurement data from the data acquisition system to monitor and control software, control commands from the monitoring software to the data acquisition system. Computer networks in the other microcomputer can also through the monitoring host forwarding see fan monitoring interface. PC system block diagram is shown in figure 4.

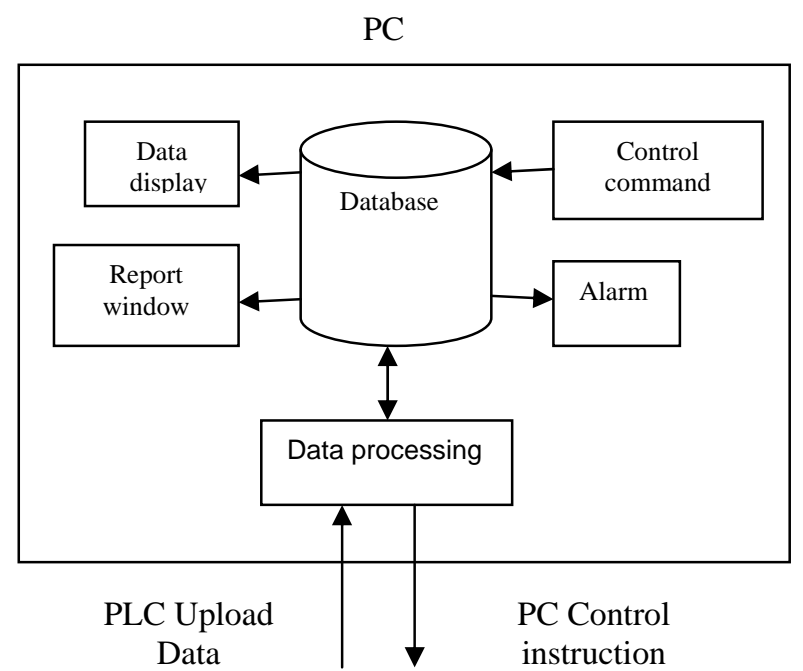

Figure4. PC System block diagram

PLC software uses ladder diagram language, clear and easy to understand simple and intuitive, and easy to modify. Program design uses the modular structure, convenient repair and expansion. Through the sensor to complete the fan entrance pressure air, bearing. Temperature, blower vibration strength parameter acquisition converses to PLC, control or alarm signals are outcome after processing, figure 5 for the simulation data acquisition subroutine. 


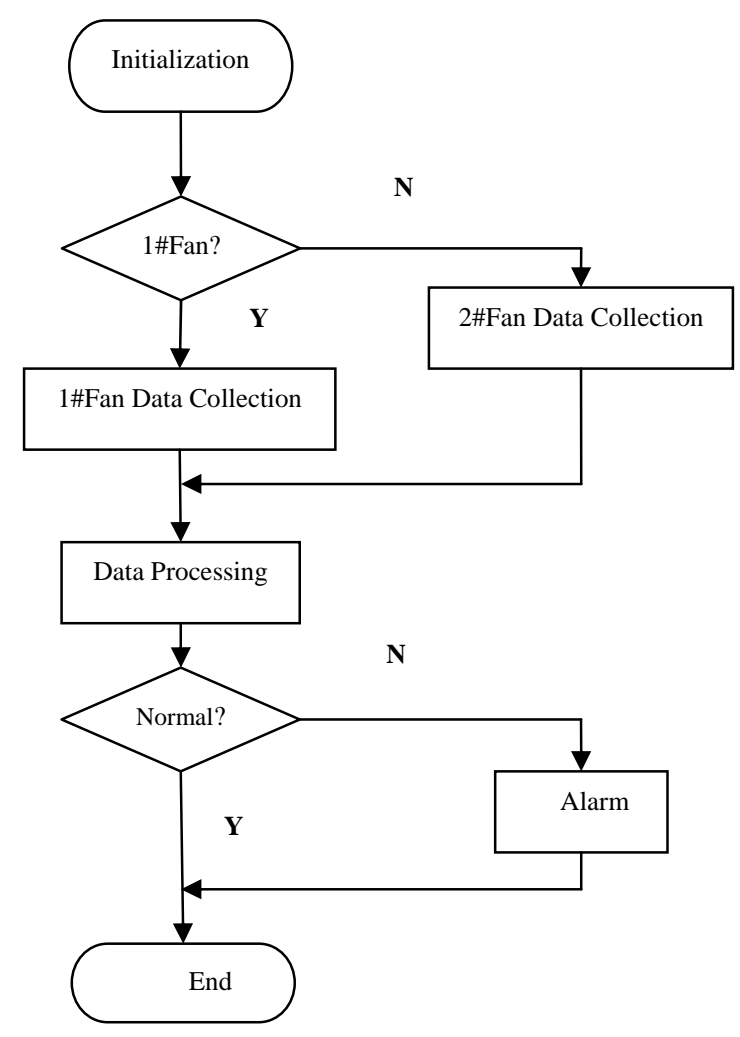

Figure5. Simulation data acquisition and processing flow chart

\section{CONCLUSION}

The system is controlled by the industrial control computer as the core, with a variety of peripheral equipment, under the control of software, data acquisition, analysis, charts and other form are displayed on a display device, and transmits it to a designated location. The PLC system is mainly to complete data acquisition and fan start / stop control. Based on the VC++ and SQL Server PC control system can ensure the fan monitoring system reliability and real time. To improve the system of integrated automation system of coal mine information, intelligence levels have a certain role in promoting

\section{REFERENCE}

[1] ZHANG Yongchao, "Research on Computer monitor system of the fan,” [D] Shandong University of Science and Technology, June 2003.

[2] FANG Liguo, HUA Gang, ZHANG Pei and QI Weijuan, "Main fan on-line monitoring and control system design", Journal of Huaiyin Institute of Technology, 2009, 18(1)23-26.

[3] WANG Qili, HU Yafei, XIONG Jianjun "Based on the programmable controller main coal mine ventilator monitoring and management system,”[J] Coal Engineering, 2007,(7)94-96.

[4] MA Ruijun, "Coal mine ventilator monitoring and management software system design,"'[J] Automation Instrumentation, 2008,29(10)37-39. 